\title{
Nest box selection and reproduction of European Rollers in Central Italy: a 7-year study
}

\author{
Flavio Monti ${ }^{1,3^{*}} \mathbb{D}$, Luca Nelli ${ }^{2}$, Carlo Catoni ${ }^{1}$ and Giacomo Dell'Omo ${ }^{1}$
}

\begin{abstract}
Background: Changes and increased mechanisation of agricultural practices have influenced the biodiversity composition of farmland habitats and caused a decline of bird communities in many European countries. The removal of shrubs and large trees rich in natural cavities, has also led to a drastic decrease in nest site availability for cavity-nesting bird species. Nest-boxes are a common conservation tool used to improve nest-site availability, and have helped to reverse declines in many endangered bird populations. Nonetheless to maximize the results of such interventions it is crucial to know where nest-boxes should be sited. The objective of this study was to investigate the effectiveness of the nest-box program for the European Roller (Coracias garrulus) population of Lazio region (Central Italy). More specifically, we focused on what landscape features were preferred (or avoided) in the process of nest box selection and how they influenced population's breeding parameters. Particular attention was paid to identifying potential limitations and to provide management recommendations for future interventions.

Methods: Using data from 70 nest boxes sited on power lines monitored over a 7-year period (representing 140 breeding attempts), we developed probability functions to evaluate if nest box location, in terms of distance from habitat resources and habitat composition and structure, had an effect on nest box occupancy and on the main reproductive parameters.
\end{abstract}

Results: Nest boxes were more likely to be occupied if they were located near arable fields and in areas characterized by a higher amount of incoming solar radiation. Higher fledging success was associated with fallow fields and with a moderate/low habitat structural complexity. Higher breeding success was associated with solar radiation and with greater distance from urban areas.

Conclusions: Our results highlight the importance of specific habitat variables in influencing nest occupancy, and show which drivers primarily affect species' reproduction and persistence over time. Siting nest boxes in habitats where occupancy rate and fledging success is higher, such as in arable and fallow fields and on south-facing slopes where solar radiation is maximised, may help to extend the suitable habitat for rollers and facilitate its local expansion.

Keywords: Breeding parameters, Coracias garrulus, Farmland birds, Habitat selection, Nest-boxes, Power lines

\section{Background}

In recent decades, changes in agricultural practices have modified the landscape structure at local and regional-scales in many European countries (e.g. Donald et al. 2006; Butler et al. 2010). Such changes, including

\footnotetext{
*Correspondence: flaviomonti00@gmail.com

${ }^{1}$ Ornis Italica, Piazza Crati 15, 00199 Rome, Italy

Full list of author information is available at the end of the article
}

specialisation of farms, simplification of crop rotations, increased mechanisation and agrochemical use (Benton et al. 2003) have influenced the biodiversity composition of farmland habitats (Chamberlain et al. 2000) and resulted in changes in the ecology, phenology and diversity of assemblages of invertebrate species (e.g. Hunter 2002). The abundance and availability of invertebrates have declined with agricultural intensification and mechanization, leading to declines in populations of 
farmland and grassland bird species (Benton et al. 2003). In Europe, farmland birds are indicative of the wider biodiversity decline associated to modern agricultural activities (Donald et al. 2001; Nikolov et al. 2011; Morelli et al. 2014). By feeding chiefly on large insects, many insectivorous bird species such as the Lesser Kestrel (Falco naumanni), the Lesser Grey Shrike (Lanius minor), and the European Roller (Coracias garrulus), have suffered greatly from habitat loss caused by changing agricultural practices (Franco and Sutherland 2004; Giralt et al. 2008; Kerus and Racinskis 2008; Tiefenbach 2009; Butler et al. 2010).

Furthermore the rationalization of agriculture, which entails the removal of shrubs and large trees rich in natural cavities, has also led to drastic decrease in nest site availability for cavity-nesting bird species (Kovács et al. 2008). Many studies have shown that the abundance of suitable holes can be a limiting factor for reproduction in cavity-nesting birds even in habitats in which food is abundant (Newton 1994; Blanco et al. 1997). In this context, the installation of nest-boxes is a common conservation tool to overcome shortage of natural nesting places and has often resulted in an increase in the local breeding density of cavity-nesters (Avilés et al. 1999; Catry et al. 2013). Such direct management measures, together with specific corrections of agricultural practices, have helped to reverse declines in many endangered bird populations (e.g. Avilés and Costillo 1998; Gottschalk et al. 2011). However, in any nest-box program, evaluating the effectiveness of the nest boxes is of paramount importance (Finch et al. 2018). For example, unfavourable nest box locations or unproductive sites may slow the recovery of threatened populations (Gottschalk et al. 2011). Adequate management actions are therefore essential in any nest box programme in order to enhance the breeding success of the target population.

Here, we focused on a bird species typical of agricultural landscapes, the European Roller (hereafter "roller"; Cramp 1985; Finch 2016). The roller is a secondary cavitynesting bird that frequents agricultural and natural environments such as pastures, crops and meadows (Cramp 1985). Its presence is closely linked to the availability of cavities for nesting and large insects (mainly Orthoptera) for feeding (Cramp 1985). Roller populations suffered a significant decline in many European countries over the past 50 years (Kovács et al. 2008; BirdLife International 2017); cases of local extinction were recorded in Finland, Denmark, Germany, and Czech Republic (Cramp 1985). Direct conservation actions in several countries have contributed to national recoveries (BirdLife International 2017). Accordingly, the status of the European Roller has recently been downlisted from Near Threatened to Least Concern (BirdLife International 2017). However, the species is still thought to be declining in Europe, albeit at a less severe rate, and thus deserves protection (BirdLife International 2017).

In Italy, the roller population has suffered a drastic reduction $(>30 \%)$ over the last 30 years, especially in the northern part of the country (Lovari 1975; Birdlife International 2015) although a moderate increase at a national scale has been recently recorded (Pezzo and Puglisi 2015). There are approximately 1000 breeding pairs, mostly concentrated in specific areas in central and southern Italy (Pezzo and Puglisi 2015) with a few scattered isolated re-colonisations of very recent origin in more northern areas (such as Emilia Romagna, Piemonte and Friuli Venezia Giulia; Meschini 2015).

The objective of this study was to investigate the effectiveness of the nest-box program for the European Roller (Coracias garrulus) population of Lazio region (Central Italy). Particular attention was paid to identifying potential limitations and to provide management recommendations for future interventions. We used data collected over a 7-year study period on birds breeding in nest boxes on power lines. In particular, we looked at two different, but not mutually-exclusive, mechanisms affecting the breeding ecology of this species. Firstly, we evaluated what landscape features are preferred (or avoided) in the process of nest box selection: the occupancy of nest boxes was investigated in relation to distance from habitat resources, habitat composition and several environmental variables (e.g. solar radiation). This information is important in increasing the effectiveness of nest box projects, since nest boxes can be removed from sites that are usually avoided and relocated to preferred sites. This might increase the true availability of nesting cavities for the breeding population. Secondly, we investigated if different rates of reproductive parameters, such as clutch size and fledging success, were associated with the location of nest boxes and to the landscape features surrounding it. This information can help to optimize the breeding success of the population when using the same number of nest boxes in a nest-box programme (Gottschalk et al. 2011).

Finally, since individuals of the same species may respond and adapt differently to local environmental characteristics and landscape features (Morelli 2013), we compared our results with published data from other European Rollers populations (i.e. Rodriguez et al. 2011; Kiss et al. 2014; Catry et al. 2017; Finch et al. 2018), in order to assess whether the species benefits from similar habitat characteristics at breeding grounds across the geographical range or if it adapts to different local environmental features/resources. 


\section{Methods}

\section{Study area and census methods}

About 70 breeding pairs (mostly breeding on man-made artefacts such as farmhouse ruins, barns or in low voltage electricity poles) were estimated to be present in the whole Lazio region (Central Italy) in 2009 and in 2015 (Brunelli et al. 2011; Pezzo and Puglisi 2015). Since 2010 the Italian national electric power company Terna S.p.A. has installed seventy nest boxes specifically designed for rollers on metal pylons of high voltage power lines, across the provinces of Rome and Viterbo in the Lazio region, in order to improve nest site-availability for the species (Fig. 1). The mean distance between each pylon and the nearest one is $445 \pm 171.5 \mathrm{~m}$ (SD). Birds breeding in nest boxes in these areas were our study population. The area contains both intensive arable farmland and organic cereal crops, fragmented by grasslands with bushes and trees: urban artefacts are present but in low density. Other habitats include fallow fields mainly used for livestock rearing and olive groves.

The nest boxes have been monitored every year, for seven years between 2010 and 2016. In order to assess the nest boxes occupancy, each nest box was periodically checked during the breeding season (one visit per week between the end of April and the end of July). A nest box was considered occupied if at least one egg was laid by a roller (e.g. Finch 2016); unoccupied if remained empty for the whole season or occupied by another species [e.g. Common Starling (Sturnus vulgaris), House Sparrow (Passer domesticus)].

For each nest box, we recorded: (a) clutch size (i.e. number of eggs laid), (b) number of hatched eggs and (c) number of fledged chicks. From these parameters, we calculated the hatching success (young hatched/eggs laid), the fledging success (young fledged/eggs hatched), and the annual breeding success (young fledged/eggs laid). In some cases, nest boxes could not be monitored, resulting in reproductive data being only partially available for that nest boxes (e.g. years 2013 and 2014). These latters were included in the analyses only for the available data.

\section{Environmental data}

The habitat characteristics of the area surrounding each nest box were analysed with the Geographic Information System (GIS) open source software QGIS (QGIS Development Team. QGIS Geographic Information System. Open Source Geospatial Foundation Project 2018). We measured the habitat composition in an area of 600 $\mathrm{m}$ radius around the nest box to investigate the foraging habitat type and to evaluate habitat preferences in the breeding area. This corroborates with previous estimates of the foraging range size of breeding rollers (approximately $600 \mathrm{~m}$ based on Finch (2016), Saunders (2016) and Catry et al. (2017)). For the habitat variables we used the Corine Land Cover (Büttner and Kosztra 2007) and we grouped them into seven categories, using the 3rd level classification: urban areas, orchards (including olive groves and wineyards), fallow fields, scrubland, arable fields (including cereals), forest, and grassland (Table 1). We measured the Euclidean distance from each nest box to the nearest patch of each habitat variable. Furthermore, we calculated the percentage of each habitat variable in a circular plot around each nest box, using a radius of $600 \mathrm{~m}$, as described above. Then, since high environmental temperatures can affect the physiological status of nestlings resulting in severe fitness costs (Catry et al. 2015), we analysed the solar radiation at nest sites to evaluate possible effects on the various breeding parameters. More specifically, using a $10 \mathrm{~m}$ digital elevation model (Tarquini et al. 2007, 2012), we calculated the average altitude of each plot and, using the Potential Incoming Solar Radiation tool for Saga GIS (Conrad et al. 2015), the total amount of incoming solar radiation in the area covered by each circular plot (600 m buffer). The solar radiation, expressed in $\mathrm{Wh} / \mathrm{m}^{2}$, was calculated for the nesting period, and it was defined as a product of daily and seasonal shift of sun angle, along with variation in elevation, orientation (slope and aspect), and shadows cast by topographic features. We also evaluated the habitat structure at the considered scale, using the Lecos tool for QGIS (Jung 2016) to calculate the following landscape metrics: Shannon diversity index, number of patches (NumP), mean patch size (MPS), mean perimeter/area ratio (MPAR), and edges density (ED). All habitat variables and landscape metrics are listed in Table 1.

\section{Statistical analysis and model selection}

To investigate the effect of habitat on nest box occupancy, clutch size, hatching, fledging, and breeding success, we performed five series of generalized linear mixed effects models (GLMMs). As response variable, we used nest box occupancy (1 if occupied by rollers, 0 if not), hatching success (calculated as proportion of hatched eggs over the number of laid eggs), fledging success (proportion of fledged young on hatched eggs) and breeding success (proportion of fledged young on laid eggs), under a binomial distribution, whereas for clutch size we used the number of laid eggs under a Poisson distribution. Calendar year was included as a random factor, to account for possible annual differences in meteorological conditions that could affect the parameters of interest. As each nest was sampled for consecutive years, we also included the nest ID as a further random term in each model. The availability of power lines was not used as additional 

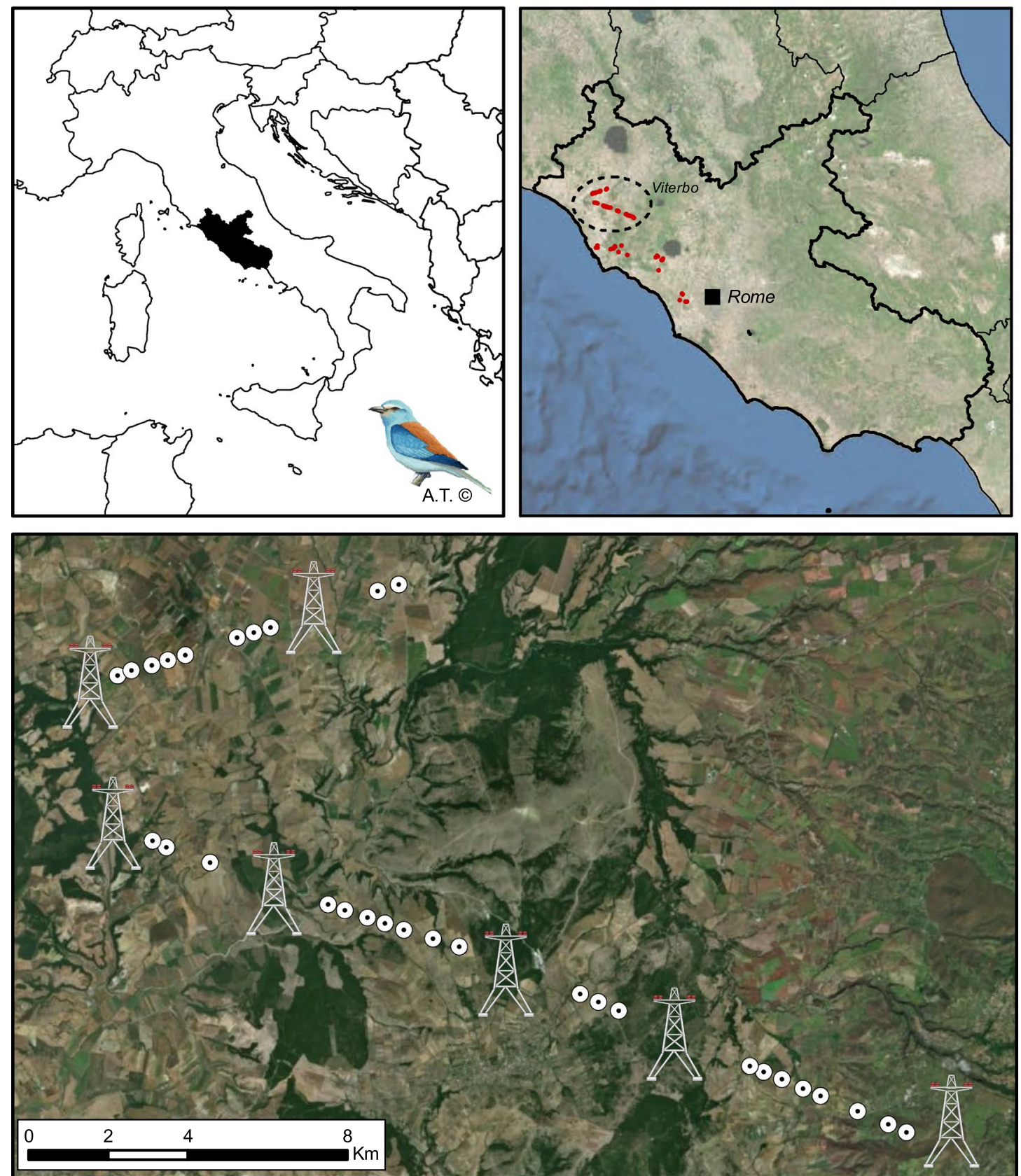

Fig. 1 Study area and location of nest boxes (black dots) distributed between Rome and Viterbo provinces, in Lazio region (Central Italy). The area surrounded by the dotted circle (containing nest boxes of the Viterbo province) is zoomed in the bottom panel

predictor because all nest boxes were installed on power lines, limiting expected variation between sites for this parameter. To select the habitat variables for inclusion in each model we used an information theoretic approach based on the corrected value of Akaike's information criterion $\left(\mathrm{AIC}_{\mathrm{c}}\right.$ ) (Burnham and Anderson 2002) with multi-model inference. To exclude correlation among variables in the same models, we identified all the subsets of uncorrelated $(p>0.05)$ predictor variables by calculating a matrix of Pearson correlation coefficients and performed the multi-model inference starting from those pre-selected subsets. The model with the lowest $\mathrm{AIC}_{\mathrm{c}}$ was elected as the best, with the others ranked according to their $\mathrm{AIC}_{\mathrm{c}}$ difference from this $\left(\triangle \mathrm{AIC}_{\mathrm{c}}\right)$. Furthermore, we measured the relative importance of models by their Akaike weights ( $w_{i}$; Anderson et al. 2000, 2001). Finally, 
Table 1 Predictor variables used to model the occupancy and the productivity of European Rollers in artificial nest boxes in Lazio region, Central Italy

\begin{tabular}{|c|c|}
\hline Habitat variables & Definitions \\
\hline \multicolumn{2}{|l|}{ Nest position } \\
\hline Distance from arable fields (including cereals) & $\begin{array}{l}\text { Euclidean distances between the nest box and the nearest patch } \\
\text { of the given habitat type }\end{array}$ \\
\hline \multicolumn{2}{|l|}{ Distance from urban areas } \\
\hline \multicolumn{2}{|c|}{ Distance from orchards (including olive groves and wineyards) } \\
\hline \multicolumn{2}{|c|}{ Distance from scrublands } \\
\hline \multicolumn{2}{|l|}{ Distance from fallow fields } \\
\hline \multicolumn{2}{|l|}{ Distance from forests } \\
\hline \multicolumn{2}{|l|}{ Distance from grasslands } \\
\hline \multicolumn{2}{|l|}{ Terrain } \\
\hline Altitude & Meters above sea level \\
\hline Solar radiation & Amount of solar radiation, expressed in $\mathrm{Wh} / \mathrm{m}^{2}$ \\
\hline \multicolumn{2}{|l|}{ Habitat composition } \\
\hline$\%$ of arable fields & $\begin{array}{l}\text { Percentage of each habitat variable in a circular buffer of } 600 \mathrm{~m} \text { of } \\
\text { radius around the nest box }\end{array}$ \\
\hline \multicolumn{2}{|l|}{$\%$ of scrublands } \\
\hline \multicolumn{2}{|l|}{$\%$ of fallow fields } \\
\hline \multicolumn{2}{|l|}{$\%$ of urban areas } \\
\hline \multicolumn{2}{|l|}{$\%$ of orchards } \\
\hline \multicolumn{2}{|l|}{$\%$ of forests } \\
\hline \multicolumn{2}{|l|}{$\%$ of grasslands } \\
\hline \multicolumn{2}{|l|}{ Habitat structure (landscape metrics) } \\
\hline Shannon diversity & Measure of relative patch diversity in the $600 \mathrm{~m}$ buffer \\
\hline Number of patches (NumP) & Total number of patches in the $600 \mathrm{~m}$ buffer \\
\hline Mean patch size (MPS) & Average patch size in the $600 \mathrm{~m}$ buffer \\
\hline Mean perimeter/area ratio (MPAR) & Shape complexity in the $600 \mathrm{~m}$ buffer \\
\hline Edges density (ED) & Amount of edge relative to the landscape area in the $600 \mathrm{~m}$ buffer \\
\hline
\end{tabular}

we used model averaging of models with $\Delta \mathrm{AIC}_{\mathrm{c}}<7$ (Burnham et al. 2011) from the top model to obtain the model averaged coefficients of predictor variables and to rank them according to their predictive importance $(\Sigma w$, sum of Akaike's weights). Preliminary manipulation of environmental layers was done using the software QGIS (QGIS Development Team 2018); the model fitting and the multi-model inference was carried out in the statistical environment R ( $R$ Development Core Team 2018) via the packages lme4 (Bates et al. 2015) and MuMIn (Barton 2016). Other results are reported as mean \pm standard deviations.

\section{Results}

We analysed data from a total of 140 occupied nest boxes across a 7-year period (from 2010 to 2016). The studied roller population gradually increased from ca. 15 occupied nest boxes in 2010 to 33 in 2016 (mean: $20 \pm 8.8$ occupied nest boxes; Table 2; Fig. 2). In 2015, the roller population produced a maximum of 112 chicks that fledged successfully (mean number of chicks per year during the study period: $53.28 \pm 30.05$ chicks; Fig. 2). To compare results between years, reproductive parameters were calculated on nest boxes for which complete data were available (see details on Table 2). The roller population produced on average $5.03 \pm 0.48$ eggs per occupied nest box. The mean number of eggs hatched and chicks fledged per nest box was $3.90 \pm 0.78$ and $3.74 \pm 0.76$, respectively. During the study period, the mean annual breeding success, calculated as young fledged/eggs laid, was $0.73 \pm 0.23$. Other reproductive parameters are reported in Table 2.

\section{Effects of habitat variables on nest boxes occupancy}

The most important variables affecting nest boxes occupancy were the distance from arable fields and the edge density. Both were present in the top ranked models (totaling a predictive importance $\Sigma w=0.76$, with a significant negative coefficient). This indicates that nest boxes close to arable fields and in larger patches (low 
edge density) had a higher probability to be occupied. In particular, nest boxes at $0 \mathrm{~m}$ distance from arable fields had an average predicted probability of being occupied of $65.8 \%$, whereas the furthest nest, which was $1800 \mathrm{~m}$ from arable fields, had an $11.0 \%$ probability. The effect of arable fields was also shown by the significant and positive coefficient of the percentage of arable fields in the $600 \mathrm{~m}$ plot surrounding the nest, although its predictive importance was lower $\left(\sum w=0.24\right)$. Solar radiation in the area surrounding the nest box was positively associated with nest occupancy, although with a moderately-low predictive importance $(\Sigma w=0.24)$. Proximity to orchards positively affected nest occupancy too, with the same predictive importance but the $95 \%$ confidence interval of the estimated coefficient overlapped the 0 value, indicating a non-significant effect (Fig. 3; Additional file 1: Table S1 and S2).

\section{Effects of habitat variables on reproductive parameters}

Clutch size was not particularly affected by the considered habitat variables. Among all the considered models describing the number of laid eggs, a null model (i.e. including intercept only) was ranked as the best one, in terms of AIC (Additional file 1: Table S3). The top ranked habitat variables were distance from fallow fields and orchards, both with a negative coefficient, suggesting that pairs breeding in proximity to these habitats were likely to lay a higher number of eggs. However, these were not statistically significant and the low sum of Akaike's weights (respectively 0.20 and 0.16 ) indicated a low importance of such predictors (Fig. 3; Additional file 1: Table S4).

For hatching success, the total amount of incoming solar radiation in the $600 \mathrm{~m}$ circular plot surrounding the nest was the most important variable $\left(\sum w=1.00\right)$, being present in all the best models with $\triangle \mathrm{AIC}<7$, and it showed a significant and positive effect on the expected proportion of hatched eggs with an expected increase from $75.7 \%$ in nest boxes with the lowest incoming solar radiation to $97.7 \%$ in nest boxes with the highest. Percentage of orchards in the $600 \mathrm{~m}$ buffer was the second ranked variable for predictive importance $(\Sigma w=0.58)$, with a negative effect. The negative and significant coefficient of distance from grassland indicates that nest boxes close to grassland had a higher expected proportion of hatched eggs (Fig. 3; Additional file 1: Table S5 and S6).

For fledging success, percentage of fallow fields in the $600 \mathrm{~m}$ circular plot around the nest box was the only habitat variable present in almost all the best models, as shown by its sum of Akaike's weight $\left(\sum w=0.98\right)$. The positive and significant coefficient of this variable indicates that pairs breeding in an area surrounded by fallow fields had a higher proportion of fledged young.
Altitude was the second ranked variable $(\Sigma w=0.64)$ and it had a positive effect. Habitat structure seems to play a moderate role, and the positive effect of mean patch size $(\Sigma w=0.52)$ suggests that habitats with moderate/low complexity are associated with a higher fledging success (Fig. 3; Additional file 1: Table S7 and S8).

Because most losses occurred at the egg stage, results for overall breeding success were similar to those for hatching success. Breeding success, was strongly associated with incoming solar radiation, which showed a high importance $\Sigma w=1$ and a significant and positive effect. Percentage of orchards in the $600 \mathrm{~m}$ buffer had a high importance $(\Sigma w=0.96)$ and its coefficient indicates that nest boxes surrounded by orchards have a lower expected breeding success. Other variables with a moderate predictive importance were distance from arable fields $(\Sigma w=0.49)$, percentage of urban areas $\left(\sum w=0.37\right)$ and distance from grassland $\left(\sum w=0.32\right)$, all with a positive effect although they failed to reach statistical significance (Fig. 3; Additional file 1: Table S9 and S10).

\section{Discussion}

In our study area, the roller population showed a gradual increase in the number of reproductive pairs that occupied nest boxes provided on power lines. Nowadays, this population consists of about 30-33 reproductive pairs. The colonization of nest boxes represents an increase in the local range of the species. In the whole Lazio region, about 70 pairs were estimated in 2009 and 2015 (Brunelli et al. 2011; Meschini 2015). Although it is not possible to fully exclude that some pairs have moved from natural sites to nest boxes, we think that the majority of the pairs in nest boxes are new, since most of the historical pairs are still faithful to their own nests and their numbers remained fairly constant during the study period, as per regional surveys and field observations (Brunelli et al. 2011; Meschini 2015; Catoni unpubl. data). Furthermore, nest boxes were not placed close to extant breeding pairs of rollers. Therefore, we are confident that the pairs in our nest boxes are new and should be added to the estimates of the overall roller population in the region.

The absence of large trees rich in natural cavities due to the recent intensification of agricultural practices probably limited the availability of suitable hollows for nesting. The shortage of natural shelters resulted in a quick occupancy of the new nest boxes provided. Our results are in line with previous studies, which showed the importance of artificial nest boxes for the conservation of the species, especially in those areas where landscape composition was intensively modified by changes in agricultural practices (e.g. southern Hungary; Kiss et al. 2016; south Iberia; Catry et al. 2017). 


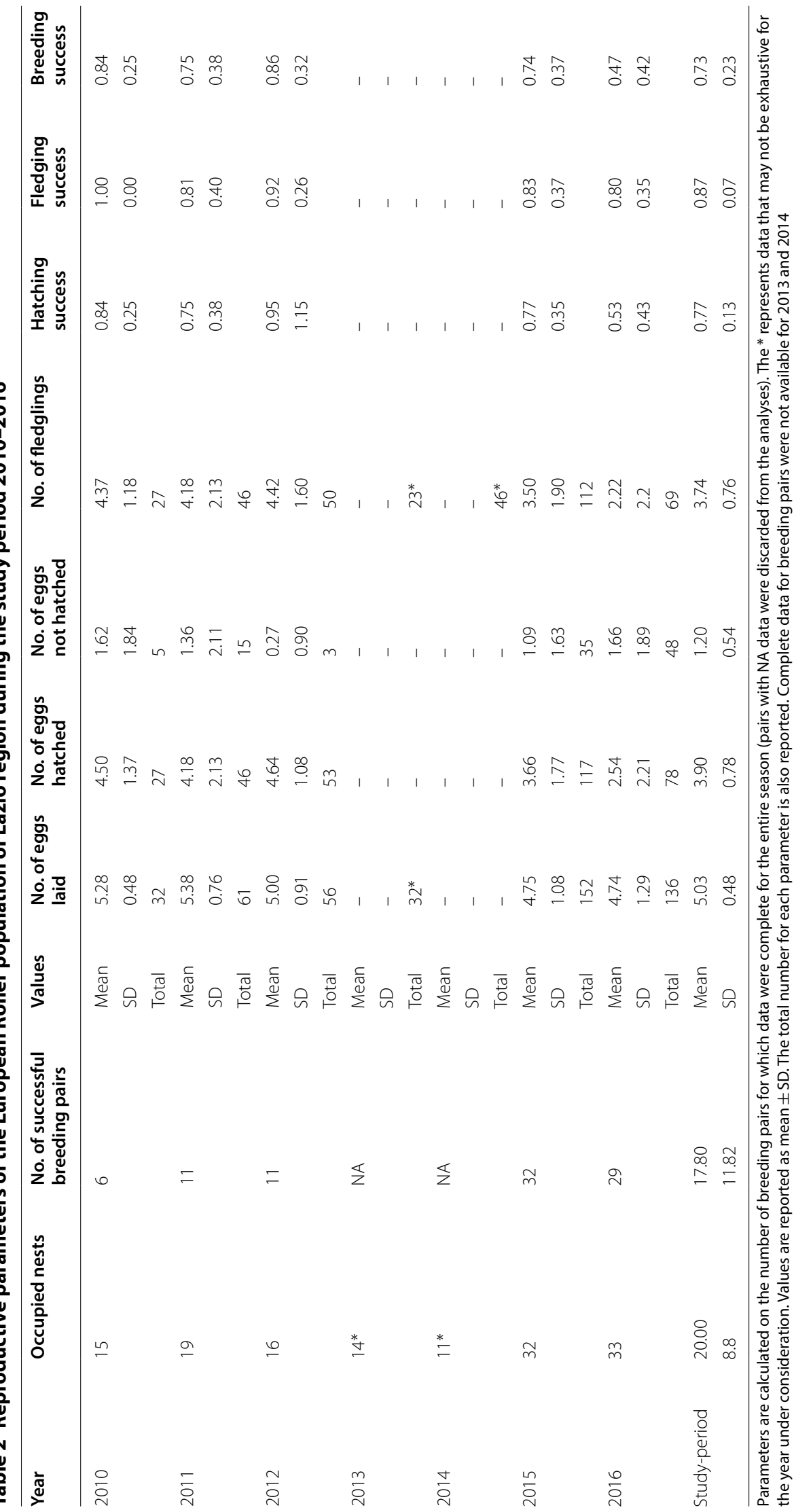




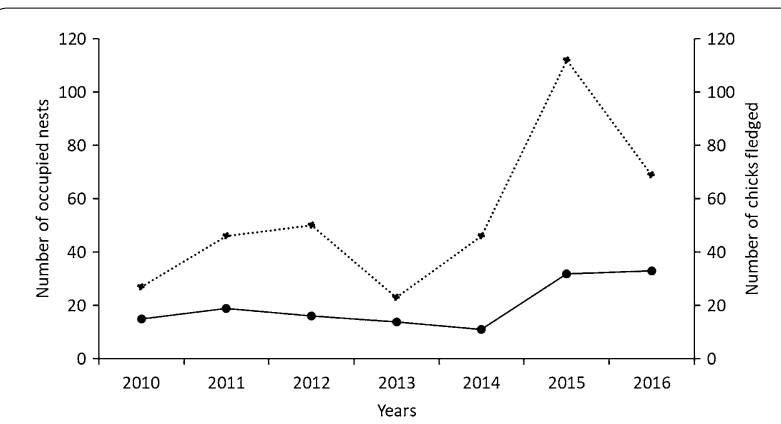

Fig. 2 Number of occupied nests (i.e. breeding pairs that laid at least one egg) and number of chicks fledged are reported as black and dotted line, respectively. Data refer to the study area and the study period 2010-2016

However, the effectiveness of nest-boxes is maximised in areas where foraging resource availability is not a limiting factor. In a comparative study on two distant rollers populations, Finch et al. (2018) demonstrated that factors driving variation in breeding density and nest-box occupancy were different between populations: the Latvian population was influenced by foraging resources availability while the French one mostly by nesting resources. This means that context-dependent conservation interventions may be necessary and might vary across the species' range where local populations might be limited by different factors. This highlights the importance of evaluating conservation actions on each population, in different parts of rollers' breeding range (Kiss et al. 2014). In our specific case, nest boxes' installation has proved to be a good means for encouraging the rollers' reproduction and local range expansion.

\section{Effects on nest box occupancy}

Habitat variables can play an important role in influencing the choice of nest sites, and thus in shaping the

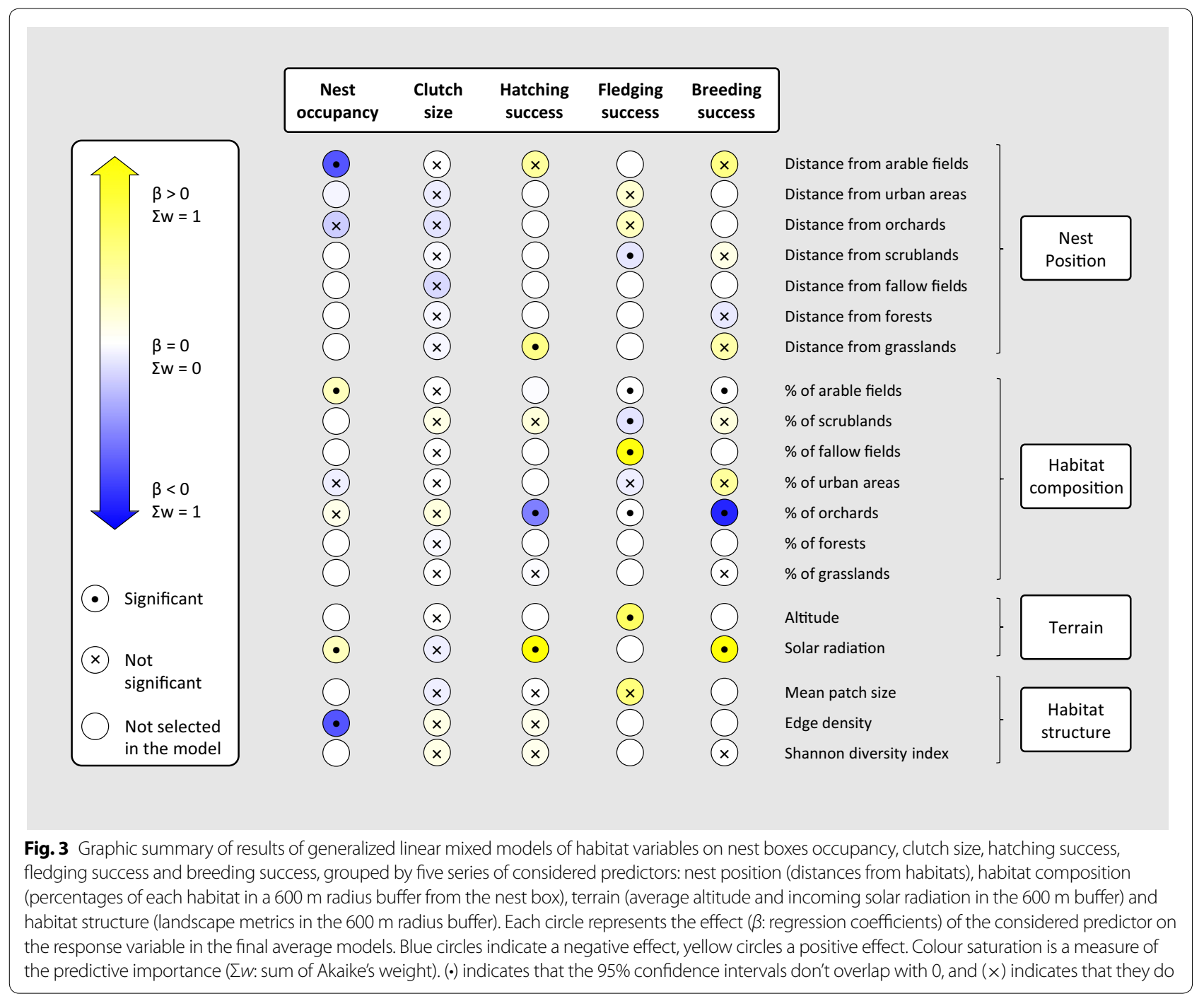


species distribution at a local scale. Factors such as nest location, habitat patch composition and presence of conspecifics and/or predators are known to highly affect nest site selection in European Roller (Parejo and Avilés 2011; Vaclav et al. 2011; Parejo et al. 2013; Bouvier et al. 2014).

In our case, we found that nest boxes in farmland habitats consisting predominantly of arable fields and located in moderately sun-exposed areas had a higher probability of being occupied by rollers. A similar study conducted in southern Hungary showed how such man-made habitats seem to be offering a high-quality breeding habitat for the species (Kiss et al. 2014): in that study, rollers showed higher breeding performance in agricultural areas (where more than $50 \%$ of the area was made of arable fields) than in their traditional habitat of natural "steppe" grasslands, because of the higher availability of prey species (different species of insects and small vertebrates).

\section{Effects on reproductive parameters}

Landscape composition affected nest box occupancy and also had important effects on the reproductive performance of the breeding pairs. However, these effects were not the same for all the reproductive parameters. More specifically, we found that none of the habitat variables were of importance in predicting the expected numbers of eggs laid per pair. Once a nest box was occupied, the habitat variables had a minor impact on the clutch size. We could hypothesize that, all nest boxes being identical in terms of internal space and size, the expected variation between sites for this parameter has been limited. In future it would be useful to test for differences in clutch sizes between artificial nest boxes of different sizes and natural nest sites which may differ in terms of structure and internal space for laying and incubating eggs (Evans et al. 2002; Lambrechts et al. 2010).

The hatching success was higher in areas where a higher incoming solar radiation was recorded. This is the first study to show such an effect in this species. Relatively high temperatures during the incubation phase may favour chick embryo development and subsequent egg hatching (Parejo et al. 2015). Rollers usually start incubating after that the third egg has been laid (hatching is hence asynchronous), so that parents may leave the eggs unattended for short periods (Cramp 1985; Parejo et al. 2012). In this sense, high temperatures (typical of the climate which characterizes our study area) can maintain eggs in the right conditions during periods when parents are away from the nest, thereby assuring the embryonic survival/growth. In addition, rollers can adjust hatching asynchrony in response to spring climatic conditions and resources availability (Parejo et al. 2015): high spring temperature determines food availability because it favours insect development and outbreaks. It has also been documented that roller nestlings can cope with the constraints imposed by occasional heat waves, being more tolerant/resilient to high environmental temperatures than other sympatric species such as the Lesser Kestrels (Falco naumanni) (Catry et al. 2015). All this means that high temperatures are also important during the first phases of parental cares and food provisioning after the hatching, when chicks are not yet able to properly thermoregulate.

The fledging success was positively associated with fallow fields, indicating that nest boxes closer to these patches had a higher proportion of fledged birds. At the same time, nest boxes located in areas with lower landscape complexity also showed a higher fledging success. This is counterintuitive, as in other studies (e.g. Avilés and Parejo 2004; Kiss et al. 2016), habitat heterogeneity was a positive factor for fledging success. However, this unexpected result may be explained by the fact that prey species richness and abundance in fallow and arable fields was already very high in our area, and likely sufficient to sustain chick rearing. Furthermore, areas with higher habitat structure included larger areas of woodland and pastures, which possibly had lower prey abundance than freshly threshed arable fields and mowed fallow fields. In our study area, pastures are usually much overgrazed, and therefore show very poor soil structure and consequently low amounts of large invertebrates (van Klink et al. 2015), while woodland is not a primary foraging habitat for rollers (Cramp 1985). Finally, the breeding success was higher when nest boxes were sited in areas with higher incoming solar radiation and when relatively distant from orchards and urban areas. This is in accordance with other studies who found that nest boxes located near urban areas or where human disturbance is high, are not selected for nesting and/or yield low breeding success (Tiefenbach 2009; Rodriguez et al. 2011).

Overall, these results show that both the composition and the configuration of the landscape are fundamental to the occurrence of breeding rollers as well as the subsequent reproductive performance, and thus the long term sustainability and resilience of local populations. We also found that specific factors differently influence the two mechanisms, such as the nest site selection and reproductive success, during the breeding season. In particular, a good solar irradiation, arable fields and a moderate/ low habitat matrix complexity appear to facilitate rollers' occurrence and provide suitable foraging resources for chick rearing, and thus to ensure the success of reproduction. 


\section{Conclusions}

Due to the severe threats currently affecting farmland bird species (Teillard et al. 2015; BirdLife International 2017), proactive management activities that aim to halt the decline of habitat heterogeneity due to land consolidation and agricultural intensification in combination with an uncontrolled rural development, seem to be essential for protecting remaining roller populations at the European level (Finch 2016). At the same time, conducting studies at a local scale in different geographic areas within the species' distributional range, can help to understand which drivers primarily affect species' distribution and persistence over time and which conservation measures can be applied for effective management (Kiss et al. 2014; Finch et al. 2018). In this sense, an understanding of the relative importance of different limiting factors on population variation, and the mechanisms underpinning these, is crucial for conservation (Finch et al. 2018).

This study contributes to the optimization of conservation measures for the species, in particular to the most effective placement of nest boxes in the study area and at other places characterized by similar habitat composition. Our results indicated that the effectiveness of the investigated nest-box program could be improved: for example, in 2015 and 2016 only $46.4 \%$ and $47.8 \%$ of available nest boxes were occupied, respectively. In order to maximise the effectiveness of conservation interventions, we propose an integrated management approach aiming at first at enhancing the availability of nest boxes and successively to put efforts into increasing reproductive success by an optimized placement of nest boxes. Specifically, the success of this nest-box program could be substantially increased if unoccupied nest boxes were relocated to sites where occupancy is more likely, and if unproductive nest boxes were relocated to locations that would enhance breeding success, as already proposed for other cavity-nesting species (e.g. Little Owl (Athene noctua); Gottschalk et al. 2011). For example, nest-boxes in habitats where occupancy rate and fledging success are higher, such as in arable and fallow fields and on south-facing slopes where presumably solar radiation is maximised, may help to extend the suitable habitat for rollers. Yet, from a more practical point of view, management actions such as the installation of new nest boxes, especially in areas of contiguity between reproductive nuclei, are of fundamental importance to support the connectivity of breeding areas and promote the extension of the distributional range over time. Last but not least, future conservation plans at local scale, should also focus on the requalification of agricultural habitats and promote sustainable agricultural practices which take into consideration the quality of farmland habitats and its related biodiversity.

\section{Additional file}

Additional file 1: Table S1. Selected $(\triangle \mathrm{AIC}<7)$ generalized linear mixed models of habitat variables on European Roller's nest box occupancy in Lazio region (Italy). Table S2. Model-averaged coefficients ( $\beta$ ) with 95\% confidence intervals $(\mathrm{LCl}, \mathrm{UCl})$ of generalized linear mixed models of habitat variables on European Roller's nest box occupancy in Lazio region (Italy), ranked by their predictive importance $(\Sigma w)$. Table $\mathbf{S 3}$. Selected $(\triangle \mathrm{AIC}<7)$ generalized linear mixed models of habitat variables on European Roller's clutch size in Lazio region (Italy). Table S4. Model-averaged coefficients $(\beta)$ with $95 \%$ confidence intervals $(\mathrm{LCl}, \mathrm{UCI})$ of generalized linear mixed models of habitat variables on European Roller's clutch size in Lazio region (Italy), ranked by their predictive importance $(\Sigma w)$. Table S5. Selected $(\triangle \mathrm{AIC}<7)$ generalized linear mixed models of habitat variables on European Roller's hatching success in Lazio region (Italy). Table S6. Model-averaged coefficients ( $\beta$ ) with $95 \%$ confidence intervals $(\mathrm{LCl}, \mathrm{UCl})$ of generalized linear mixed models of habitat variables on European Roller's hatching success in Lazio region (Italy), ranked by their predictive importance $(\Sigma w)$. Table $\mathbf{S 7}$. Selected $(\triangle \mathrm{AIC}<7)$ generalized linear mixed models of habitat variables on European Roller's fledging success in Lazio region (Italy). Table S8. Model-averaged coefficients ( $\beta$ ) with 95\% confidence intervals $(\mathrm{LCl}, \mathrm{UCl})$ of generalized linear mixed models of habitat variables on European Roller's fledging success in Lazio region (Italy), ranked by their predictive importance $(\Sigma W)$. Table $\mathbf{S 9}$. Selected $(\triangle \mathrm{AIC}<7)$ generalized linear mixed models of habitat variables on European Roller's breeding success in Lazio region (Italy). Table S10. Model-averaged coefficients $(\beta)$ with $95 \%$ confidence intervals $(\mathrm{LCl}, \mathrm{UCl})$ of generalized linear mixed models of habitat variables on European Roller's breeding success in Lazio region (Italy), ranked by their predictive importance $(\Sigma w)$.

\section{Authors' contributions}

FM led the study, collected data on the field, prepared and analysed population data and wrote the manuscript. LN did all the statistical analyses and model selection of environmental data and wrote related results. CC collected data on the field and helped with the discussion. GD helped with the study design and the writing. All authors read and approved the final manuscript.

\section{Author details}

${ }^{1}$ Ornis Italica, Piazza Crati 15, 00199 Rome, Italy. ${ }^{2}$ Institute of Biodiversity Animal Health and Comparative Medicine, University of Glasgow, Glasgow G12 8QQ, UK. ${ }^{3}$ Department of Physical Sciences, Earth and Environment, University of Siena, Strada Laterina, 8, 53100 Siena, Italy.

\section{Acknowledgements}

This work was carried out within the collaboration "Nests on Power lines" between Terna Rete Italia SpA and Ornis italica. In particular, we thank Alberto Olivieri, Nicoletta Rivabene and Luca Moiana for their support to the field activities. We also thank Tim Mackrill for valuable comments on a first draft of the manuscript and Alessandro Troisi for the drawing of the European Roller in Fig. 1

\section{Competing interests}

The authors declare that they have no competing interests.

\section{Availability of data and materials}

The datasets used and/or analysed during the current study are available from the corresponding author on reasonable request.

Consent for publication

Not applicable. 
Ethics approval and consent to participate

Not applicable.

\section{Funding}

Not applicable.

Received: 12 September 2018 Accepted: 29 March 2019

Published online: 21 April 2019

\section{References}

Anderson DR, Burnham KP, Thompson WL. Null hypothesis testing: problems, prevalence, and an alternative. J Wildl Manag. 2000;64:912-23.

Anderson DR, Link WA, Johnson DH, Burnham KP. Suggestions for presenting the results of data analysis. J Wildl Manag. 2001;65:373-8.

Avilés JM, Costillo E. Selection of breeding habitats by the Roller (Coracias garrulus) in farming areas of the southwestern Iberian Peninsula. Vogelwarte. 1998;39:242-7.

Avilés JM, Parejo D. Farming practices and roller Coracias garrulus conservation in south-west Spain. Bird Conserv Int. 2004;14:173-81.

Avilés JM, Sanchez JM, Sanchez A, Parejo D. Breeding biology of the roller Coracias garrulus in farming areas of the southwest Iberian Peninsula. Bird Study. 1999;46:217-23.

Barton K. MuMIn: multi-model inference. R package version 1.15.6; 2016. https ://CRAN.R-project.org/package=MuMln. Accessed 9 May 2018.

Bates D, Maechler M, Bolker B, Walker S. Fitting linear mixed-effects models using Ime4. J Stat Softw. 2015;67:1-48.

Benton TG, Vickery JA, Wilson JD. Farmland biodiversity: is habitat heterogeneity the key? Trends Ecol Evol. 2003;18:182-8.

BirdLife International. European red list of birds. Cambridge: BirdLife International; 2015.

BirdLife International. Coracias garrulus (Amended version published in 2016). The IUCN red list of threatened species; 2017

Blanco G, Fargallo JA, Tella JL, Cuevas JA. Role of the buildings as nest-sites in the range expansion and conservation of Choughs Pyrrhocorax pyrrhocorax in Spain. Biol Conserv. 1997;79:117-22.

Bouvier JC, Muller I, Génard M, Françoise L, Lavigne C. Nest-site and landscape characteristics affect the distribution of breeding pairs of European Rollers Coracias garullus in an agricultural area of Southeastern France. Acta Ornithol. 2014;49:23-32

Brunelli M, Sarrocco S, Corbi F, Sorace A, Boano A, De Felici S, Guerrieri G, Meschini A, Roma S. Nuovo atlante degli uccelli nidificanti nel Lazio. Roma: Agenzia Regionale Parchi del Lazio; 2011.

Burnham KP, Anderson DR. Model selection and multimodel inference: a practical information-theoretic approach. 2nd ed. New York: Springer; 2002

Burnham KP, Anderson DR, Huyvaert KP. AIC model selection and multimodel inference in behavioral ecology: some background, observations, and comparisons. Behav Ecol Sociobiol. 2011;65:23-35.

Butler SJ. Nest-site selection by the European Roller (Coracias garrulus) in southern France. Master's Thesis. UK: University of York; 2001.

Butler SJ, Boccaccio L, Gregory RD, Vorisek P, Norris K. Quantifying the impact of land-use change to European farmland bird populations. Agric Ecosyst Environ. 2010;137:348-57.

Büttner G, Kosztra B. CLC 2007 technical guidelines. EEA technical report; 2007. p. 66

Catry I, Franco AMA, Rocha P, Alcazar R, Reis S, Cordeiro A, Ventim R, Teodósio $J$, Moreira F. Foraging habitat quality constrains effectiveness of artificial nest-site provisioning in reversing population declines in a colonial cavity nester. PLOS ONE. 2013;8:e58320.

Catry I, Catry T, Patto P, Franco AMA, Moreira F. Differential heat tolerance in nestlings suggests sympatric species may face different climate change risks. Clim Res. 2015;66:13-24.

Catry I, Marcelino J, Franco AMA, Moreira F. Landscape determinants of European roller foraging habitat: implications for the definition of agrienvironmental measures for species conservation. Biodivers Conserv. 2017;26:553-66

Chamberlain DE, Fuller RJ, Bunce RGH, Duckworth JC, Shrubb M. Changes in the abundance of farmland birds in relation to the timing of agricultural intensification in England and Wales. J Appl Ecol. 2000;37:771-88.
Conrad O, Bechtel B, Bock M, Dietrich H, Fischer E, Gerlitz L, Wehberg J, Wichmann V, Böhner J. System for automated geoscientific analyses (SAGA) v. 2.1.4. Geosci Model Dev. 2015;8:1991-2007. https://doi.org/10.5194/ gmd-8-1991-2015.

Cramp S. The birds of the western palearctic, terns to woodpeckers, vol. 4 Oxford: Oxford University Press; 1985.

Donald PF, Green RE, Heath MF. Agricultural intensification and the collapse of Europe's farmland bird populations. Proc R Soc B Biol Sci. 2001;268:25-9.

Donald PF, Sanderson FJ, Burfield IJ, van Bommel FPJ. Further evidence of continent-wide impacts of agricultural intensification on European farmland birds, 1990-2000. Agric Ecosyst Environ. 2006;116:189-96.

Evans MR, Lank DB, Boyd WS, Cooke F. A comparison of the characteristics and fate of barrow's goldeneye and bufflehead nests in nest boxes and natural cavities. Condor. 2002;104:610-9.

Finch T. Conservation ecology of the European roller. Ph.D. Thesis. UK: University of East Anglia; 2016.

Finch T, Branston C, Clewlow H, Dunning J, Franco AM, Račinskis E, Schwartz T, Butler SJ. Context-dependent conservation of the cavity-nesting European Roller. Ibis. 2018. https://doi.org/10.1111/ibi.12650.

Franco AMA, Sutherland WJ. Modelling the foraging habitat selection of lesser kestrels: conservation implications of European Agricultural Policies. Biol Conserv. 2004;120:63-74

Giralt D, Brotons L, Valera F, Kristin A. The role of natural habitats in agricultural systems for bird conservation: the case of the threatened Lesser Grey Shrike. Biol Conserv. 2008:17:1997-2012.

Gottschalk TK, Ekschmitt K, Wolters V. Efficient placement of nest boxes for the little owl (Athene noctua). J Raptor Res. 2011:45:1-14.

Hunter MD. Landscape structure, habitat fragmentation, and the ecology of insects. Agric For Entomol. 2002:4:159-66.

Jung M. LecoS-a python plugin for automated landscape ecology analysis. Ecol Inform. 2016:31:18-21.

Kerus V, Racinskis E. The second Latvian Breeding Bird Atlas 2000-2004: preliminary results. Rev Catalana d'Ornitol. 2008;24:100-6.

Kiss O, Elek Z, Moskát C. High breeding performance of European Rollers Coracias garrulus in heterogeneous farmland habitat in southern Hungary. Bird Study. 2014;61:496-505.

Kiss O, Tokody B, Deák B, Moskát C. Increased landscape heterogeneity supports the conservation of European rollers (Coracias garrulus) in southern Hungary. J Nat Conserv. 2016;29:97-104

Kovács A, Barov B, Orhun C, Gallo-Orsi U. International species action Plan for the European Roller Coracius Garrulus Garrulus. Besenyotelek, Hungary. MME/BirdLife Hungary and BirdLife International for the European Commission; 2008. http://ec.europa.eu/environment/nature/conservation/ wildbirds/action_plans/docs/coracias_garrulus_garrulus.pdf.

Lambrechts MM, Adriaensen F, Ardia DR, Artemyev AV, Atiénzar F, Banbura J, Barba E, Bouvier J-C, Camprodon J, Cooper CB, et al. The design of artificial nestboxes for the study of secondary hole-nesting birds: a review of methodological inconsistencies and potential biases. Acta Ornithol. 2010:45:1-26.

Lovari S. The roller (Coracias garrulus L.) in Italy: a bird in need of protection. Biol Conserv. 1975:8:19-22.

Meschini A. Atti del I Convegno nazionale sulla Ghiandaia marina Coracias garrulus "Un lampo turchese di interesse comunitario". Canale Monterano (RM), 20 settembre 2014. Alula. 2015;XXII(1-2):1-144.

Morelli F. Quantifying effects of spatial heterogeneity of farmlands on bird species richness by means of similarity index pairwise. Int J Biodivers. 2013. https://doi.org/10.1155/2013/914837.

Morelli F, Jerzak L, Tryjanowski P. Birds as useful indicators of high nature value (HNV) farmland in Central Italy. Ecol Indic. 2014;38:236-42.

Newton I. The role of nest sites in limiting the numbers of hole-nesting birds: a review. Biol Conserv. 1994;70:265-76.

Nikolov SC, Demerdzhiev DA, Popgeorgiev GS, Plachiyski DG. Bird community patterns in sub-Mediterranean pastures: the effects of shrub cover and grazing intensity. Anim Biodiv Conserv. 2011:34:11-21.

Parejo D, Avilés JM. Predation risk determines breeding territory choice in a Mediterranean cavity-nesting bird community. Oecologia. 2011;165:185-91.

Parejo D, Avilés JM, Rodriguez J. Supplemental food affects egg size but not hatching asynchrony in rollers. Behav Ecol Sociobiol. 2012;66:1097-105. 
Parejo D, Avilés JM, Pena A, Sanchez L, Ruano F, ZamoraMunoz C, MartinVivaldi M. Armed rollers: does nestling's vomit function as a defence against predators? PLOS ONE. 2013;8:e68862.

Parejo D, Avilés JM, Exposito M. Hatching asynchrony and spring climatic conditions in the European Roller. Evol Biol. 2015;42:443-51.

Pezzo F, Puglisi L. Aumento ed espansione della ghiandaia marina Coracias garrulus in Toscana. In: Meschini A, editor. Alula. Atti del I Convegno nazionale sulla Ghiandaia marina Coracias garrulus "Un lampo turchese di interesse comunitario", Vol. XXII, No. 1-2. Canale Monterano (RM); 2015. p. 133-135.

QGIS Development Team. QGIS Geographic Information System. Open Source Geospatial Foundation Project; 2018.

R Development Core Team. R: a language and environment for statistical computing. R Foundation for Statistical Computing, Vienna; 2018.

Rodriguez J, Avilés JM, Parejo D. The value of nest boxes in the conservation of Eurasian Rollers Coracias garrulus in southern Spain. Ibis. 2011;153:735-45.

Saunders P. Habitat change and climate effects on the European Roller (Coracias garrulus); implications for conservation. Ph.D. Thesis. UK: University of East Anglia; 2016.
Tarquini S, Isola I, Favalli M, Mazzarini F, Bisson M, Pareschi MT, Boschi E. TINITALY/01: a new Triangular Irregular Network of Italy. Ann Geophys. 2007;50:407-25.

Tarquini S, Vinci S, Favalli M, Doumaz F, Fornaciai A, Nannipieri L. Release of a 10-m-resolution DEM for the Italian territory: comparison with globalcoverage DEMs and anaglyph-mode exploration via the web. Comput Geosci. 2012;38:168-70.

Teillard $F$, Jiguet $F$, Tichit $M$. The response of farmland bird communities to agricultural intensity as influenced by aggregation. PLOS ONE. 2015;10:e0119674.

Tiefenbach M. Habitat Selection in Foraging European Rollers (Coracias Garrulus L.) in Eastern Austria. Master's Thesis. Vienna: University of Vienna; 2009.

Vaclav R, Valera F, Martinez T. Social information in nest colonisation and occupancy in a long-lived, solitary breeding bird. Oecologia. 2011;165:617-27. van Klink R, van der Plas F, van Noordwikj CGE, WallisDeVries MF, Olff H. Effects of large herbivores on grassland arthropod diversity. Biol Rev. 2015:90:347-66.
Ready to submit your research? Choose BMC and benefit from:

- fast, convenient online submission

- thorough peer review by experienced researchers in your field

- rapid publication on acceptance

- support for research data, including large and complex data types

- gold Open Access which fosters wider collaboration and increased citations

- maximum visibility for your research: over 100M website views per year

At BMC, research is always in progress.

Learn more biomedcentral.com/submissions 